\title{
Effect of vulcanizer solution on the blood lipid profile of Wister albino rats
}

\author{
Otitoju Olawale and Moses A. Abah * \\ Department of Biochemistry, Faculty of Pure and Applied Sciences, Federal University Wukari, Taraba State, Nigeria.
}

GSC Biological and Pharmaceutical Sciences, 18(02), 052-057

Publication history: Received on 24 November 2021; revised on 03 February 2022; accepted on 05 February 2022

Article DOI: https://doi.org/10.30574/gscbps.2022.18.2.0046

\begin{abstract}
Inhalant abuse is a worldwide problem that is common especially in individuals from minority and marginalized populations, and is strongly correlated with the social determinants of health. The abuse of inhalants such as vulcanizer solutions among Nigerian youths, for the purpose of mind-alteration or getting high is on the increase at an alarming rate. These inhalants are pharmacologically diverse products that are selected for their low price, legal and widespread availability, and ability to rapidly induce euphoria. The aim of this research was to subject wistar albino rats to different vulcanizer solutions and investigate the possible effects of these solutions on the social behavior as well as significant changes in the concentrations of blood lipid profile parameters (TChol, TAG, HDL, and LDL). A commercial assay kit from Randox laboratories Ltd was used for the determination of the parameters. The acute effects of administration of the vulcanizer solution through inhalation on the High density lipoprotein level of albino rats showed that rats administered with Miliki diamond solution (group A) $\left(1.1 \pm 0.04^{\mathrm{a}}\right)$ and OSHN diamond solution (group D) (1.0 $\left.\pm 0.03^{\mathrm{a}}\right)$ is statistically significant $(\mathrm{p}<0.05)$ having lower High density lipoprotein compared to the control group (E) $\left(1.4 \pm 0.85^{\mathrm{b}}\right)$. There was an increase in the level of total cholesterol in group D (OSHN diamond) ( $5.2 \pm 0.35^{\text {a }}$ ) which is not statistically significant $(\mathrm{P}<0.05)$ compared to the control groups $(\mathrm{E})\left(4.8 \pm 0.10^{\mathrm{a}}\right)$. The results also showed a decrease in the level of low density lipoprotein in all test groups compared to the control group which is not statistically significant $(\mathrm{P}<0.05)$. On the chronic inhalation, there were significant increase $(\mathrm{p}<0.05)$ in the total Cholesterol level of group $D$ animals $\left(4.5 \pm 0.08^{\mathrm{c}}\right)$ compared to the control group $\left(4.3 \pm 0.29^{\mathrm{b}}\right)$. There was neither an increase nor a decrease in the level of total cholesterol of the remaining groups which are not statistically significant $(\mathrm{P}<0.05)$ when compared to the control group. On HDL level, only OSHN diamond solution decreased the serum. Despite the increasing and decreasing effects of these solutions, they have been shown to be statistically not significant $(\mathrm{p}<0.05)$ when compared with those of the control. The changes seen in the behavior as well as blood lipid profile of the wistar albino rats could be attributed to the effects caused by the various chemical constituents (such as toluene, benzene, ethyl, etc) of vulcanizer solutions. Therefore, abusers of vulcanizer solutions may be susceptible to various cardiovascular diseases as well as diseases of the liver and other organs, thus adding to the number of people with the aforementioned diseases in this generation.
\end{abstract}

Keywords: Blood lipid profile; Vulcanizer solution; Wistar albino rats; Inhalants and Cardiovascular diseases

\section{Introduction}

Inhalant use has been considered one of the most dangerous forms of substance abuse, ever leading to death and serious accidents [1].Every year an untold number of individuals die as a result of intentionally inhaling common, legal, everyday home, school, industrial and office products[2]. These inhalants refer to a group of psychoactive substances that transform to vapors and produce mind-altering effects. Some of these inhalants include volatile substances like nitrous oxide, chloroform and ether, fumes of aerosol spray paint or 'chroming', vulcanizing glue, butane gas from lighter refills, petrol, toluene etc $[2,3]$. The deliberate inhalation of these substances (inhalants) can cause serious harm to the integrity of the central nervous system (CNS) and disrupt normal trajectories of psychological, emotional and

\footnotetext{
*Corresponding author: Moses A Abah

Department of Biochemistry, Faculty of Pure and Applied Sciences, Federal University Wukari, Taraba State, Nigeria.
} 
neurobiological development [4]. Toluene and other abused solvents produce effects similar to that of central nervous system depressants. These effects include psychomotor impairment [5], excitation and then inhibition of locomotor activity [6] , and loss of righting reflex and sedation [7]. In addition, peripheral nerve dysfunction has been reported [8].[9] Demonstrated that intraperitonaeal injection of toluene caused a significant elevation in the rate of reactive oxygen species (ROS) generation and a reduction in glutathione (GSH) levels in the brain. Long term toluene abuse has led to neuropsychiatric and neurobehavioral disorders, which in many cases, but not all, were reversible. Some chronic toluene abusers have developed structural CNS damage [10]. Toluene levels of 500ppm are considered immediately dangerous to life and health. Also, its affinity for lipid - rich structures of nervous tissue results in CNS toxic effects within minutes [11].Due to genetic polymorphisms, some people may be more sensitive to the effects of inhaled solvents than others [11].

Toxicity can occur from unintentional or deliberate inhalation of fumes, ingestion or transdermal absorption. Solutions are commonly abused by saturating or soaking a sock or rag with spray paint or adhesives, placing it over the nose and mouth, and inhaling to get a sensation of euphoria, buzz, huffing (i.e spraying paint into a plastic bag and inhaling). With bagging exhaled air is rebreathed and resulting hypoxia and hypercarbia may add to the disoriented effect of the solvent.Chronic users of inhalants typically have histories of numerous social difficulties, disadvantaged backgrounds and high levels of psychological problems $[2,12]$, suggesting that these young people may abuse inhalants to help cope with underlying emotional and social distress. Preventing and treating affected youth is difficult due to the complex psychosocial issues that these individuals typically face (for example, unstable and dysfunctional families, state-based care, school absenteeism, forensic issues, comorbid drug use and mental health problems) [2]. Despite longstanding awareness of the significant morbidity and mortality associated with inhalant abuse, neuropharmacological research has been comparatively sparse until recently, with limited data available on neurobiological squealed or effective treatment approaches. For these reasons, inhalant are reported to be as high as 50-60\%, and appear to be associated with the isolation (both geographical and social), poverty and unemployment prominent among these marginalized groups, rather than cultural issues [3].

Changes in lipid levels have been found not only in medicated, chronic patients, but also in drug-naive patients as well as inhalant users [13].Relationship between depression and lipid disturbances has been demonstrated in a substantial body of research [14-16], and depressed patients are also found to be at higher risk of developing cardiovascular diseases [17].Despite the health problems reported to be associated with inhalants abuse, little or no report has captured the relationship between vulcanizer solution and changes in the blood profile of wistar albino rats. Therefore the primary aim of this study is to investigatethe effects of vulcanizer solution on the blood profile of Wistar albino rats

\section{Material and methods}

\subsection{Test sample}

The test sample for the study was locally produced vulcanizer solutions, "Miliki diamond, OSHN diamond, Mr. Bond and Temple".

\subsection{Experimental animals}

Wistar albino rats weighing between 120-720 g were obtained from the department of Biochemistry, Federal University Wukari, and were maintained on a commercial feed (grower's marsh) for about one week in the laboratory before commencing the experiment. The animals were divided into five groups of five rats per cage. The animals were exposed to the solutions by inhalation for about two weeks, except the control group. The animals were provided with adequate food and water supply daily. Two animals each from different group were sacrificed after 24hours of exposure. Blood samples were then collected for biochemical analysis to determine acute exposure. The remaining animals were then exposed to repeated doses of rubber solution for additional 13days. At the end of the exposure period, the animals were kept fasting for 12 hours before sacrificing and the blood samples were collected for analysis.

\subsection{Total cholesterol determination}

Total Cholesterol in blood plasma was assayed after enzymatic hydrolysis and oxidation. The indicator quinoneimineis formed from hydrogen peroxidase and 4-aminoantipyrine in the presence of phenol and peroxidase as described by [18]. 


\subsection{Low density lipoprotein determination}

LDL-C in blood plasma was determined from the difference between total cholesterol and the cholesterol content of the supernatant after precipitation of the LDL fraction by polyvinyl sulphate (PVS) in the presence of polyethyleneglycolmonomethyl ether. The concentration of the serum total cholesterol as described by [19] was used.

\subsection{High density lipoprotein determination}

LDL and VLDL are precipitated from serum by the action of a polysaccharide in the presence of divalent cations. Then, high density lipoproteins (HDL) present in the supernatant was determined. Determination of the concentration of the serum total HDL as described by [19] was used.

\subsection{Triacylglycerols determination}

Triacylglycerols in blood plasma was determined after enzymatic hydrolysis with lipase. The indicator is a quinoneimine formed from hydrogen peroxide, 4-aminophenazone and 4-chlorophenol under the catalytic influence of peroxidase.

\section{Results}

Table 1 Acute effect of toluene on blood lipid profile of wistar albino rats

\begin{tabular}{|l|l|l|l|l|l|l|}
\hline Group & $\mathbf{N}$ & Treatment & \multicolumn{4}{|c|}{ Lipid profile } \\
\hline & & & $\begin{array}{l}\text { TCHOL } \\
\mathbf{( m g / d l )}\end{array}$ & $\begin{array}{l}\text { TAG } \\
(\mathbf{m g} / \mathbf{d l})\end{array}$ & $\begin{array}{l}\text { HDL } \\
\mathbf{( m g / d l )}\end{array}$ & $\begin{array}{l}\text { LDL } \\
\text { (mg/d) }\end{array}$ \\
\hline A & 2 & Miliki Diamond & $4.7 \pm 0.04$ & $2.3 \pm 0.05$ & $1.1 \pm 0.04$ & $3.0 \pm 1.00$ \\
\hline B & 2 & Dr Bond & $4.6 \pm 0.10$ & $2.0 \pm 0.15$ & $1.1 \pm 0.12$ & $3.0 \pm 0.05$ \\
\hline C & 2 & Temple & $4.5 \pm 0.35$ & $1.9 \pm 0.10$ & $1.3 \pm 0.08$ & $2.9 \pm 0.43$ \\
\hline D & 2 & OSHN Diamond & $5.2 \pm 0.35$ & $2.2 \pm 0.25$ & $1.0 \pm 0.03$ & $3.4 \pm 1.0$ \\
\hline E & 2 & Control & $4.8 \pm 0.10$ & $2.3 \pm 0.05$ & $1.4 \pm 0.85$ & $3.4 \pm 0.24$ \\
\hline
\end{tabular}

All values are represented as mean \pm SEM, $n=2$ animals in each group, Data were analyzed by one-way ANOVA, followed by post Hoc Multiple Comparison Test.

Table 2 Chronic effect of toluene on blood lipid profile of wistar albino rats

\begin{tabular}{|l|c|l|c|c|c|c|}
\hline Group & $\mathbf{N}$ & Treatment & \multicolumn{4}{|c|}{ Lipid profile } \\
\hline & & & $\begin{array}{c}\text { TCHOL } \\
(\mathrm{mg} / \mathrm{dl})\end{array}$ & $\begin{array}{c}\text { TAG } \\
(\mathrm{mg} / \mathrm{dl})\end{array}$ & $\begin{array}{c}\mathrm{HDL} \\
(\mathrm{mg} / \mathrm{dl})\end{array}$ & $\begin{array}{c}\text { LDL } \\
(\mathrm{mg} / \mathrm{dl})\end{array}$ \\
\hline A & 2 & Miliki Diamond & $3.9 \pm 0.29$ & $1.8 \pm 0.10$ & $1.5 \pm 0.17$ & $2.3 \pm 0.29$ \\
\hline B & 2 & Dr Bond & $3.9 \pm 0.24$ & $2.2 \pm 0.25$ & $1.5 \pm 0.22$ & $2.3 \pm 0.19$ \\
\hline C & 2 & Temple & $4.3 \pm 0.60$ & $2.3 \pm 0.10$ & $1.7 \pm 0.21$ & $2.4 \pm 0.69$ \\
\hline D & 2 & OSHN Diamond & $4.5 \pm 0.08$ & $2.2 \pm 0.16$ & $1.2 \pm 0.06$ & $2.9 \pm 0.85$ \\
\hline E & 2 & Control & $4.3 \pm 0.29$ & $2.2 \pm 0.18$ & $1.5 \pm 0.14$ & $2.7 \pm 0.22$ \\
\hline
\end{tabular}

All values are represented as mean \pm SEM, $n=2$ animals in each group, Data were analyzed by one-way ANOVA, followed by post Hoc Multiple Comparison Test. 


\section{Discussion}

The use of volatile substances by youth as stimulants may pose a serious problem beyond the perceived benefits. Most solvents are easily absorbed from the blood into lipid-rich tissues and can cause widespread damage. Inhalation results in serious organ system dysfunction. Airborne chemicals and volatile molecules enter the nose and can interact with chemoreceptors in the nasal cavity, especially trigeminal and olfactory receptors [20].

Lipid profile, also called lipid panel, Coronary Risk Panel or Complete Cholesterol test is mainly used to assess the risk of developing cardiovascular diseases and also to monitor management of the afflicted [21]. Lipid profile can also be used to assess the effects of environmental contaminants on the health and well-being of persons exposed to such pollutants.

For the evaluation and analysis, five groups of wistar albino rats were studied, the acute effects of administration of the vulcanizer solution through inhalation on the High density lipoprotein level of albino rats showed that rats administered with Miliki diamond solution (group A) $\left(1.1 \pm 0.04^{\mathrm{a}}\right)$ and OSHN diamond solution (group D) $\left(1.0 \pm 0.03^{\mathrm{a}}\right.$ ) is statistically significant $(p<0.05)$ having lower High density lipoprotein compared to the control group (E) $\left(1.4 \pm 0.85^{\mathrm{b}}\right)$. This observed decrease in serum cholesterol may result from the impairment in the receptor-mediated endocytosis which prevents the binding of LDL to specific receptors that could lead to its degradation and release of cholesterol [22].

There was an increase in the level of total cholesterol in group D (OSHN diamond) (5.2 $\left.\pm 0.35^{\mathrm{a}}\right)$ which is not statistically significant $(\mathrm{P}<0.05)$ compared to the control groups $(\mathrm{E})\left(4.8 \pm 0.10^{\mathrm{a}}\right)$. The results also show a decrease in the level of low density lipoprotein in all test groups compared to the control group which is not statistically significant $(\mathrm{P}<0.05)$. The significant decrease in high density lipoprotein (HDL) level in group A and D animals, exposed to Miliki diamond and OSHN diamond respectively and the increase in both total cholesterol level and low density lipoprotein level of group D animals when compared to the control group, all agrees to the findings of [23].

On the chronic inhalation, there were significant increase $(\mathrm{p}<0.05)$ in the total Cholesterol level of group D animals $\left(4.5 \pm 0.08^{c}\right)$ compared to the control group $\left(4.3 \pm 0.29^{\mathrm{b}}\right)$. The result also shows either an increase or a decrease in the level of total cholesterol of the remaining groups which are not statistically significant $(\mathrm{P}<0.05)$ when compared to the control group. On HDL level, only OSHN diamond solution decreases the serum. Despite the increasing and decreasing effects of these solutions, they have been shown to be statistically not significant $(\mathrm{p}<0.05)$ when compared with those of the control. This observation also agrees to the findings of [23].

Lipid metabolism occurs in the liver. Cholesterol is an essential constituent in cell membranes and it is used by gland cells to make steroid hormones [24]. Liver damage can lead lipid derangement with possible disturbances of cell membrane integrity which may cause some membrane lipids to be released into the circulation. Studies have demonstrated a correlation between environmental pollution and the development of cardiovascular disease (CVD) [25].

\section{Conclusion}

In this study, the observed increase and decrease in the lipid profile of animals exposed to acute and prolonged vulcanizer solution may be due to the various harmful constituents of vulcanizer solution(such as toluene, benzene, ethyl, etc) with the major constituent been toluene. Therefore, abusers of vulcanizer solutions may be susceptible to various cardiovascular diseases as well as diseases of the liver and other organs, thus adding to the number of people with the aforementioned diseases in this generation.

\section{Compliance with ethical standards}

\section{Acknowledgments}

We want to express our thanks to Professor Otitoju Olawale, the Laboratory head for his unwavering support and guidance, and all those who contributed directly to this study.

\section{Disclosure of conflict of interest}

The authors state that there was no conflict of interest. 


\section{Statement of informed consent}

Informed consent was obtained from all individual participants included in the study.

\section{References}

[1] Chakroun R, Faidi F, Abderrazek H, Charbaji K, Nouaigui H, Ben Laiba M. Inhalant Abuse Detection and Evaluation in Young Tunisians. Journal of Forensic Sciences.2008; 53(1):232-7.

[2] Lubman DI, Hides L, Yücel M. Inhalant misuse in youth: the need for a coordinated response. Med J Aust. 2006; 185:327-330.

[3] Cairney S, Maruff P, Burns C, Currie B. The neurobehavioural consequences of petrol (gasoline) sniffing. NeurosciBiobehav Rev. 2002; 26: 81-89.

[4] Kurtzman TL, Otsuka KN, Wahl RA. Inhalant abuse by adolescents. Science. Direct-Journal of adolescent Health.2021; 8(3):170-180.

[5] Moser VC, Balster RL. The effects of inhaled toluene, halothane, 1, 1, 1, trichloroethane, and ethanol on fixedinterval responding in mice. Neurobehav. ToxicolTeratol. 1986; 8(5):525-31.

[6] Warren DA, Bowen SE, Jennings WB, Dallas CE, Balster RL. Biphasic effects of 1, 1, 1-trichloroethane on the locomotor activity of mice: relationship to blood and brain solvent concentrations. Toxicol Sci.2000; 56(2):36573.

[7] Tegeris JS, Balster RL. A comparison of the acute behavioral effects of alkylbenzenes using a function al observational battery in mice. FundamApplToxicol. 1994; 22(2): 240-50.

[8] Echeverria D, Fine L, Langolf G, Schork T, Sampaio C. Acute behavioral comparisons of toluene and ethanol in human subjects. Br J Ind Med. 1991; 48(11):750-61.

[9] Mattia CJ, Adams JD, JrBondy SC. Free radical induction in the brain and liver by products of toluene catabolism. BiochemPharmacol. 1993; 46(1):103-10.

[10] Greenberg MM. The central nervous system and exposure to toluene: a risk characterization. Environ Res. 1997;72(1):1-7.

[11] Campagna D, Stengel B, Mergler D et al. Color vision and occupational toluene exposure. NeurotoxicolTeratol. $2001 ; 23(5): 473-80$.

[12] Oetting ER, Edwards RW, Beauvais F. Social and Psychological Factors Underlying Inhalant Abuse. National Institute on Drug Abuse:Rockville, MD. 1998.

[13] Misiak B, Stanczykiewicz B, Laczmanski L, Frydecka D. Lipid profile disturbances in antipsychotic-naive patients with first-episode non-affective psychosis: a systematic review and meta-analysis. Schizophr Res.2017;190:1827.

[14] Kahl, KG, Greggersen W, Schweiger U, Cordes J, Balijepalli C, Lösch C, Moebus S. Prevalence of the metabolic syndrome in unipolar major depression. Eur Arch Psychiatry ClinNeurosci. 2012; 262(4):313-320.

[15] Persons JE, Fiedorowicz JG. Depression and serum low-density lipoprotein: a systematic review and metaanalysis. J Affect Disord. 2016; 206:55-67.

[16] Parekh A, Smeeth D, Milner Y, Thure S. The role of lipid biomarkers in major depression. Healthcare (Basel Switz). 2017; 5(1).

[17] Penninx BW, Beekman AT, Honig A, Deeg DJ, Schoevers RA, van Eijk JT, Van Tilburg W. Depression and cardiac mortality: results from a community-based longitudinal study. Arch Gen Psychiatry. 2001; 58(3):221-227.

[18] Abel LL, Levy BB, Brodie BB, Kendall FE. A simplified method for the estimation of total cholesterol in serum and demonstration of its specificity. J Biol Chem. 1952; 195(1):357 66.

[19] Kameswara BR, Kesabulu MM, Giri R, Raoch A. Antidiabetic and hypolipidaemic effects of Momordicacymbaleri a Hook fruit powder in alloxan diabetic rats. Journal of Ethnopharmacology. 1999; 67:103-109.

[20] Gobba. Occupational exposure to chemicals and sensory organs: a neglected research field. Neurotoxicology. $2003 ; 24(4-5): 675-91$. 
[21] Castelli WP, Anderson K, Wilson PW, Levy D. Lipids and risk ofcoronary heart disease: the Framingham Study.Ann Epidemiol. 1992; 2(1-2):23-28.

[22] Ubani CS, Joshua EP, Amiara VO. Toxicological effects of Kerosene contaminated diet on the lipid profile of Albino Rats. Journal of Pharmacy Research. 2010; 2:292-297.

[23] Nwafor A. Life under assault: nowhere to hide. University of Port HarcourtInaugral Lecture Series No.2013; 102.

[24] Ganong WF, Mulrow PJ. Rate of change in sodium and potassium excretion after injection of aldosterone into the aorta and renal artery of the dog. Am J Physiol. 1958; 195:337 342.

[25] Udebuani AC, Otitoju O, Akaniru CN, Nwaogu LA. Abara PN Effects of Chronic Consumption of Cola nitida on Melatonin and Enzyme Production in Albino Wistar Rats Der Pharmacia Lettre, Scholars Research Library. 2017; 9(11):7-15. 